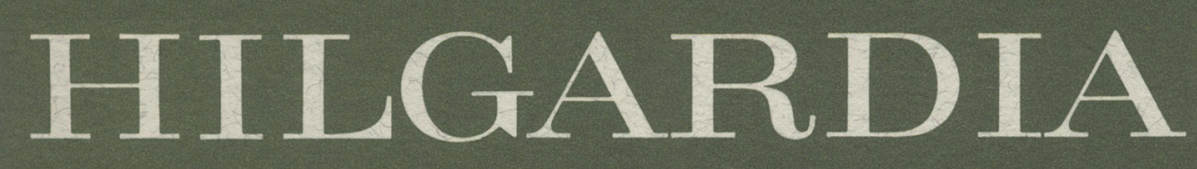

OOURNAL OF AGRICULTURAL SCIENCE PUBLISHED BY THE CALIFORNIA AGRICULTURAL EXPERIMENT STATION

Volume 44, No. 4 - November 1976

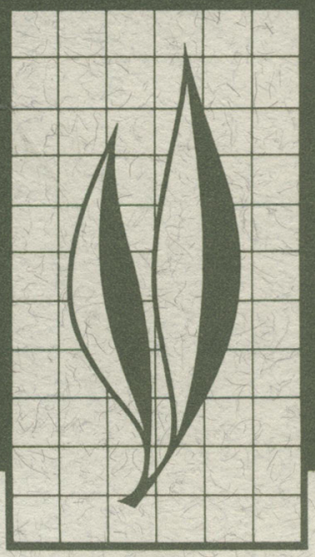

\title{
Movement of Steam Along the Sides of Containers During Steam Treatment of Soil
}

Kenneth F. Baker and William H. Fuller 


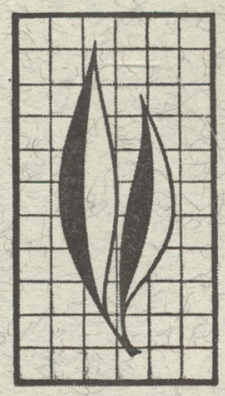

\begin{abstract}
Aerated steam and steam are commonly used for treating soil in the glasshouse, nursery, and mushroom industries to control soilborne plant pathogens. In treating soil in containers there is an important and disturbing tendency for the soil next to the container sides to attain the desired temperature more rapidly than does that in the central mass. This "edge effect" cannot be eliminated, but can be diminished by:

a) treating soil in layers not more than $30 \mathrm{~cm}$ thick; b) using large flow rates of aerated steam or steam, preferably injected through a plenum at the top; c) treating soil in beds by the Thomas or surface method or by buried perforated pipes or tiles, treating soil in flats or pots by a vault steamer, and treating bulk soil by a perforated-pipe steam box or a transit-type concrete mixer; d) inserting vertical partitions or open pipes in the central mass if a plenum-type steam box or a mobile bin and potting table is used; e) using very porous soil mixtures. Temperature measurements should be made in soil at the bottom center when steam is injected through a top plenum, and at the top center when steam injection is through a bottom plenum.
\end{abstract}

\title{
THE AUTHORS:
}

Kenneth F. Baker is Professor Emeritus in the Department of Plant Pathology, and Plant Pathologist Emeritus in the Experiment Station, Berkeley.

William H. Fuller was formerly Staff Research Associate in the Department of Plant Pathology, Experiment Station, Berkeley. 


\section{Movement of Steam Along the Sides of Containers During Steam Treatment of Soil}

Steam treatment of soil in glasshouse and nursery practice and in mushroom growing is the common method over much of the world for controlling soilborne plant pathogens. Soil under these conditions is generally confined in containers such as benches, beds, cans, pots, flats, or planter boxes. General discussions of the principles and practices of soil steaming have been published (Aldrich et al., 1974, 1975; Baker, 1969, 1971; Baker and Roistacher, 1957; Johnson and Aas, 1960; Morris, 1954a, 1954b).

It has frequently been observed in California tests over the last 20 years (Baker, 1971) that, in steam treatment of soil in a container, the steam diffuses faster along the enclosing walls, and the soil there attains the desired temperature more rapidly than does the rest of the soil mass. The effect has been more pronounced in containers with deep layers of soil than in those with $30 \mathrm{~cm}$ or less of soil. The increased rate of heating at the sides is partially offset by heat radiation from the walls of the container, particularly if it is made of metal; but even then, soil at the sides heats more rapidly than that in the center. This phenomenon has been disregarded or overlooked in many studies of soil steaming.

This so-called "edge effect" or "side effect" was aicributed by Baker (1971) to the greater soil porosity and resulting lower resistance to flow at the sides where the soil particles are in contact with a smooth surface. The soil particles tend to fit together in the center of the mass, reducing pore size and increasing resistance to steam flow.

The occurrence of this edge effect, possible practical means for decreasing it, and hypotheses of its cause are presented in this paper.

\section{MATERIALS AND METHODS}

An experimental unit was constructed that simulated the conditions of commercial treatment of bulk soil in the mobile bin and potting bench type (Type 3, Baker and Roistacher, 1957). The box unit, $91 \mathrm{~cm}$ long, $91 \mathrm{~cm}$ wide, and $61 \mathrm{~cm}$ high, was constructed of marine-grade plywood. A plenum $15 \mathrm{~cm}$ high was provided at the bottom and at the top, each with a port $10 \mathrm{~cm}$ in diameter for either input or exhaust, depending on whether steam was injected from below or above (Figs. 3, 4).
$\Lambda$ coarse, heary, metal screen, covered with saran mesh, supported the soil above the bottom plenum. This screen replaced an earlier wooden bottom perforated with $1-\mathrm{cm}$ holes, and greatly increased flow rate and decreased the time to reach the desired temperature.

A straight-blade centrifugal blower (Cincinnati Fan and Blower Co., Model PB12, kindly supplied by Stites and Hartdegen Co. of South Francisco, California) was used in these experiments. It produced, at $3300 \mathrm{rpm}$, a static pres- 
sure equal to $23 \mathrm{~cm}$ of water, and a flow of 53.3 liters/sec, when the box contained a $61-\mathrm{cm}$ layer $\left(0.51 \mathrm{~m}^{3}\right)$ of a U.C.-type soil mix (50 percent fine sand, 50 percent peat) with 20 percent moisture.

Steam flow was controlled by a manual valve, and was introduced into the air duct leading from the blower. These partially mixed gases were passed through a centrifugal drier to remove entrained water drops. In this drier, the gas mixture was tangentially introduced into a small can or drum near the bottom, and was passed out through the top to the treatment box. Entrained drops were centrifugally forced against the sides of the drum, and drained out the bottom through a steam trap (Morris, 1954a). The mixing was thorough, and the mixture was free of water drops.

Thirty-two thermocouples placed in the soil mass at various points made it possible to follow the advancing heat front through the soil. They were placed in different positions for the different configurations of treatment.

Because of variation in compaction, water content, and composition in a given soil mass, steam tends to diffuse through parts of it at different rates, and to reach the exit plenum at slightly different times. The recommendation for treatment of soil with aerated steam, i.e., maintenance of $60 \mathrm{C}$ for 30 min before cooling, provides sufficient inbuilt reserve time to compensate for these differences. However, this may not be the case for the difference (often 50 percent or more) between time of heating at the sides and heating in the center of the soil mass, particularly in layers of soil exceeding $61 \mathrm{~cm}$ in depth.

Steam and aerated steam move through soil in the same manner and at approximately the same rate (Baker and Olsen, 1960; Baker, 1967, 1969). The conclusions reached in this study with aerated steam are therefore applicable also to flowing steam of $100 \mathrm{C}$.

The data presented are the longest times required for the soil at the sides and in the central area of the soil mass at the exit plenum to reach $60 \mathrm{C}$. The percentage given in Figs. 3 and 4 is

minutes for the slowest point

at sides to reach $60 \mathrm{C}$

minutes for the slowest point in

the central mass to reach $60 \mathrm{C}$

The higher the percentage, the more uniform the rate of heating, and the better the method.

\section{RESULTS}

\section{Steam Flow Pattern, Thermally Determined}

Unmodified Steam Box.-Differential heating at the sides and center of a soil mass heated from below, reported earlier (Baker, 1971), was confirmed in these studies; a similar effect was observed when the soil was heated from above. In one test with Salinas fine sandy loam, aerated steam injected at the top required $23 \mathrm{~min}$ to reach $60 \mathrm{C}$ at the bottom central area, and $16 \mathrm{~min}$ at the bottom sides and corners, or 70 percent as long (Fig. 1). In another test with this soil and a smaller steam flow rate, $43 \mathrm{~min}$ were required for the bottom central area to reach $60 \mathrm{C}$, and $25 \mathrm{~min}$ were needed to heat the bottom sides, 58 percent as long (Fig. 2). In a third test (Fig. $3 \mathrm{~A}$ ), with a still smaller steam flow through a U.C.-type soil mix, the last point in the central bottom area to reach $60 \mathrm{C}$ required 67 $\mathrm{min}$, but only $35 \mathrm{~min}$ were required at the bottom sides, or 52 percent as long. This indicates that increasing the steam flow decreases the edge effect, as inferred by Aldrich (1971). 


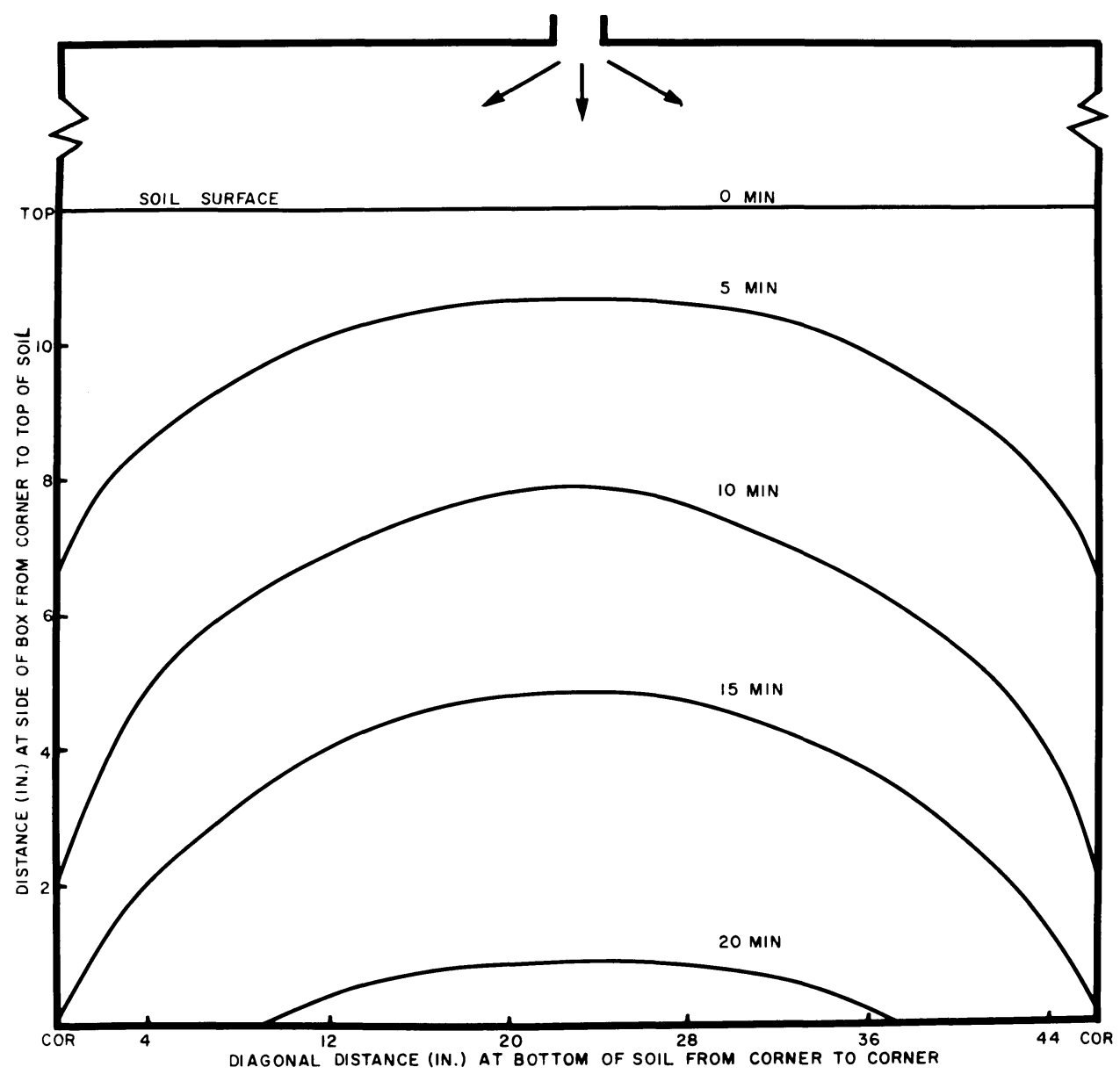

Fig. 1. Vertical section of treatment box showing $60 \mathrm{C}$ isotherms at several time intervals along diagonal lines at different levels above the bottom of the box. Salinas very fine sandy loam was used, and the aerated steam was injected at the top with a static pressure of 12 $\mathrm{cm}$ of water.

In a test with aerated steam injected through the bottom plenum, the slowest point in the central top area to reach $60 \mathrm{C}$ required $95 \mathrm{~min}$, and the sides required $52 \mathrm{~min}$, or 55 percent as long.

When aerated steam is introduced into some porous soil mixes through a bottom plenum, the greater steam flow along the container sides may lead to "blow outs" (release of steam through fluidized "chimneys" in soil) of steam there. These blowouts result when the condensing capacity of the soil (Morris,
$1954 b)$ is exceeded. This quickly drains the steam from other parts of the soil mass, practically stopping the heating there. It is partly to prevent this that steam is best introduced into bulk soil through a top plenum, since labyrinthine cavities that start to form will be plugged by soil particles falling or blowing into them. However, there is more compaction of the soil when steam is injected from above than from below (Aldrich et al., 1975). If one of the lightweight mixes is being treated, this 


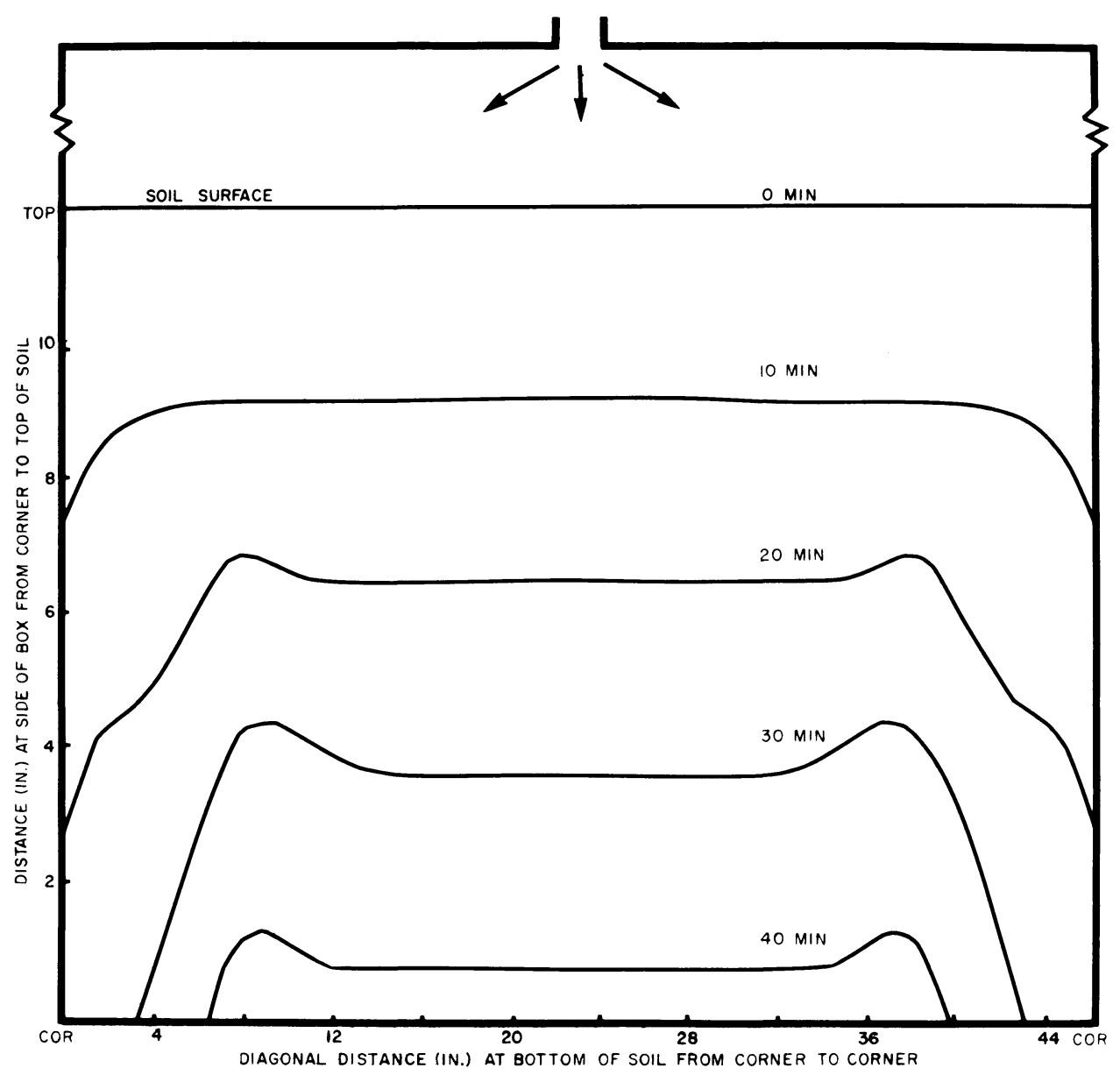

Fig. 2. Vertical section of treatment box showing $60 \mathrm{C}$ isotherms at several time intervals along diagonal lines at different levels above the bottom of the box. Salinas very fine sandy loam was used, and the aerated steam was injected at the top with a static pressure of 12 $\mathrm{cm}$ of water. Steam flow rate was lower than in the test in Fig. 1.

compaction is unimportant; but it may become restrictive when a clay soil is steamed (Aldrich et al., 1974).

Sand-Coated Sides of Steam Box.Baker (1971) thought that the edge effect was due to the greater porosity at the soil particle-side than at the soil particle-soil particle interface. To investigate this, the inner sides of the box were coated with sand cemented by epoxy resin so as to provide a surface against which the soil particles would interlock, somewhat as in the soil mass.
It was thought that the roughened surface would thus decrease the flow of aerated steam at the sides. However, aerated steam moved along these roughened surfaces at about the same time rate as along smooth surfaces. Apparently the sand-coated sides did not decrease the soil porosity at the point of contact.

Perforations in Basal Plate, with Greatest Number at the Center.-Instead of the very porous saran and wire screen at the bottom of the soil mass, a 

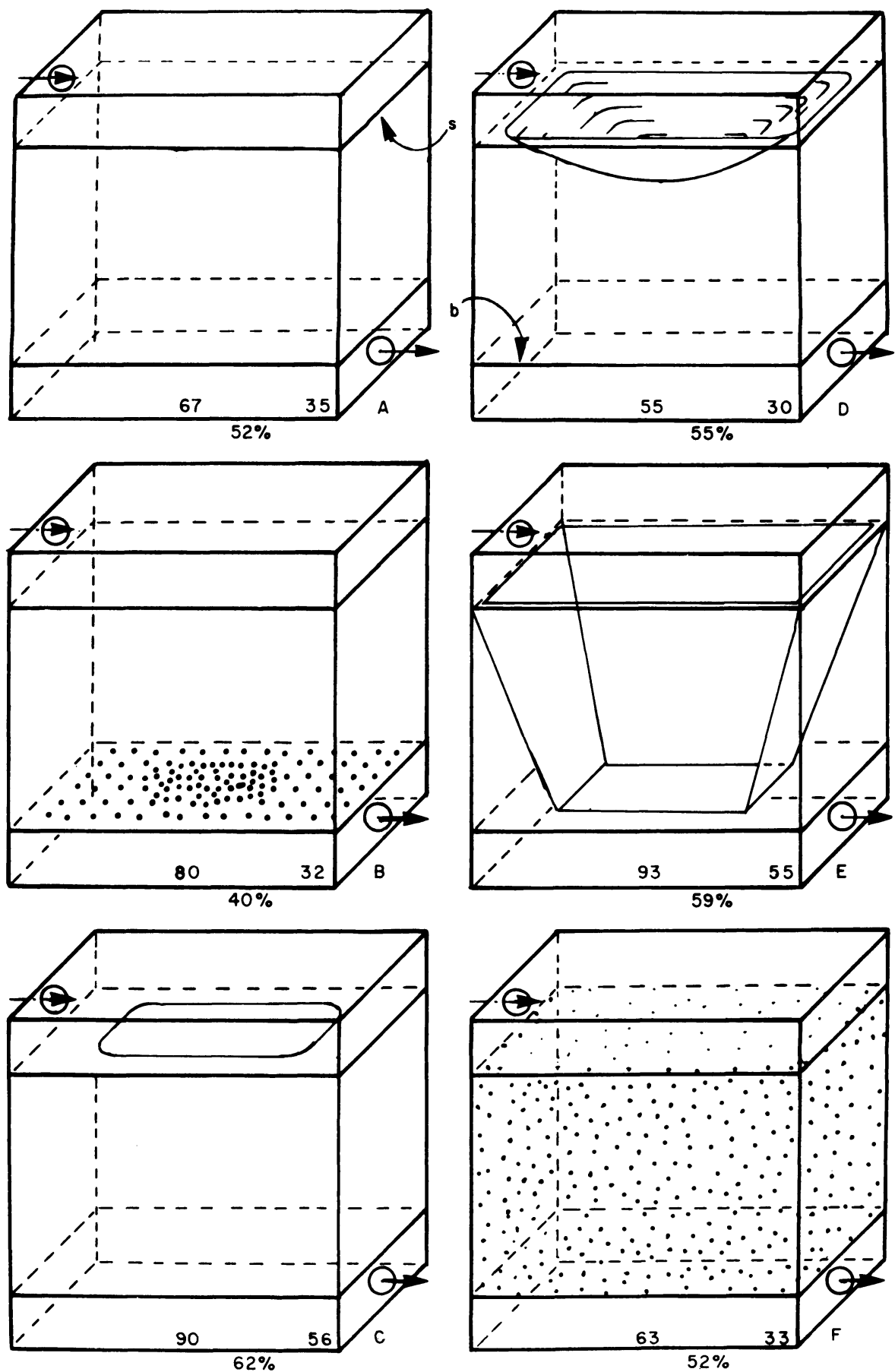

Fig. 3, A-F. Diagram of six configurations of the steam treatment box used in tests to decrease the edge effect during treatment. U.C.-type soil mix was used, and aerated steam was injected into the top plenum. Upper surface of soil $=a$; lower surface of soil $=b$. The time in minutes for the slowest point in the soil mass and at the bottom of the side to reach $60 \mathrm{C}$, and the percentage the latter is of the former, are given for each. A. Unmodified steam box. B. Perforated basal plate, with greatest number of holes at the center. C. Collar inserted under soil surface. D. Decreased soil depth at center of the box. E. Sides of the box sloped inward. F. Water added to soil at sides of box. See text for explanations. 
wooden plate perforated with holes 1 $\mathrm{cm}$ in diameter on 2.5 -cm centers was used in this test. In the central $30 \times 30$ $\mathrm{cm}$ area, the holes were on $1.5-\mathrm{cm}$ centers to increase gas movement through the center of the soil mass. The last point to reach $60 \mathrm{C}$ at the bottom required $80 \mathrm{~min}$, and at the sides $32 \mathrm{~min}$, or 40 percent as long (Fig. 3B). The aerated steam apparently flowed down the side as before. The reduced porosity of the base plate slowed the rate of heating at the center even more than at the sides.

Collar Inserted Under Upper Soil Surface.-A 15-cm wide collar of plastic sheet was attached to the sides of the box just beneath the soil surface (Fig. 3C). Aerated steam introduced into the top plenum entered the soil through the central $61 \times 61 \mathrm{~cm}$ hole. A substantial portion of the steam flowed along the lower surface of the plastic to the sides of the box, and down the sides. The slowest bottom point to reach $60 \mathrm{C}$ required $90 \mathrm{~min}$, and the sides $56 \mathrm{~min}$, or 62 percent as long. The net effect was an increased heating time throughout because the collar decreased by 55 percent the area through which the aerated steam passed.

In another test, a plastic collar with a center $30 \times 30 \mathrm{~cm}$ hole was attached to the container sides $30 \mathrm{~cm}$ from the bottom, midpoint in the soil mass. The flow of aerated steam was so severely restricted (only 10.9 percent of the crosssectional area of the box) that the soil at the bottom had not reached $60 \mathrm{C}$ in $90 \mathrm{~min}$, when the test was terminated. Thermocouple readings again indicated that the aerated steam flowed along the under surface of the collar back to the sides.

Decreased Soil Depth at Center of the Box.-We considered that if soil was excavated from the top center of the soil mass, leaving a greater depth of soil at the sides of the box (Fig. 3D), aerated steam injected at the top might reach the bottom central area and sides at about the same time. The soil was excavated as a cone $91 \mathrm{~cm}$ wide at the top and $20 \mathrm{~cm}$ deep in the center, leaving $41 \mathrm{~cm}$ of soil there ( 67.2 percent as deep as at the sides). There was a slight decrease in the time required to reach $60 \mathrm{C}$ in the bottom central area, as compared with the unmodified box. The soil mass (approximately 90 percent that of the full box) was heated in 82 percent of the time required for the full box. However, the slowest bottom point to reach $60 \mathrm{C}$ required $55 \mathrm{~min}$, whereas the sides required $30 \mathrm{~min}$, or 55 percent as long. The side-center differential was not improved over that of the unmodified box.

Sides of the Box Sloped Inward.Plywood panels were fitted inside the box to form an inverted truncated pyramid of soil in the center (Fig. 3E). The bottom end of the insert was $51 \mathrm{~cm}$ square, a 68.6 percent reduction in the cross-sectional area of the box. This insert was tested to determine whether aerated steam, flowing downward into a diminishing volume of soil, would move as rapidly in the central area as down the sides. The slowest bottom point to reach $60 \mathrm{C}$ required $93 \mathrm{~min}$, and the sides $55 \mathrm{~min}$, or 59 percent as long. The principal effect of the sloping sides, therefore, was to decrease downward flow throughout, because of the smaller bottom opening. Although 38 percent less soil was treated than in the unmodified box, the time required was 39 percent greater.

Water Added to Soil Lining the Side Walls of the Box.-Water has approximately five times the specific heat (heat capacity) of dry soil (Baker and Roistacher, 1957). If a 5-cm layer of soil lining the sides of the box was wetter (and thus had a higher heat capacity and a lower porosity) than that in the internal mass, it would heat more 

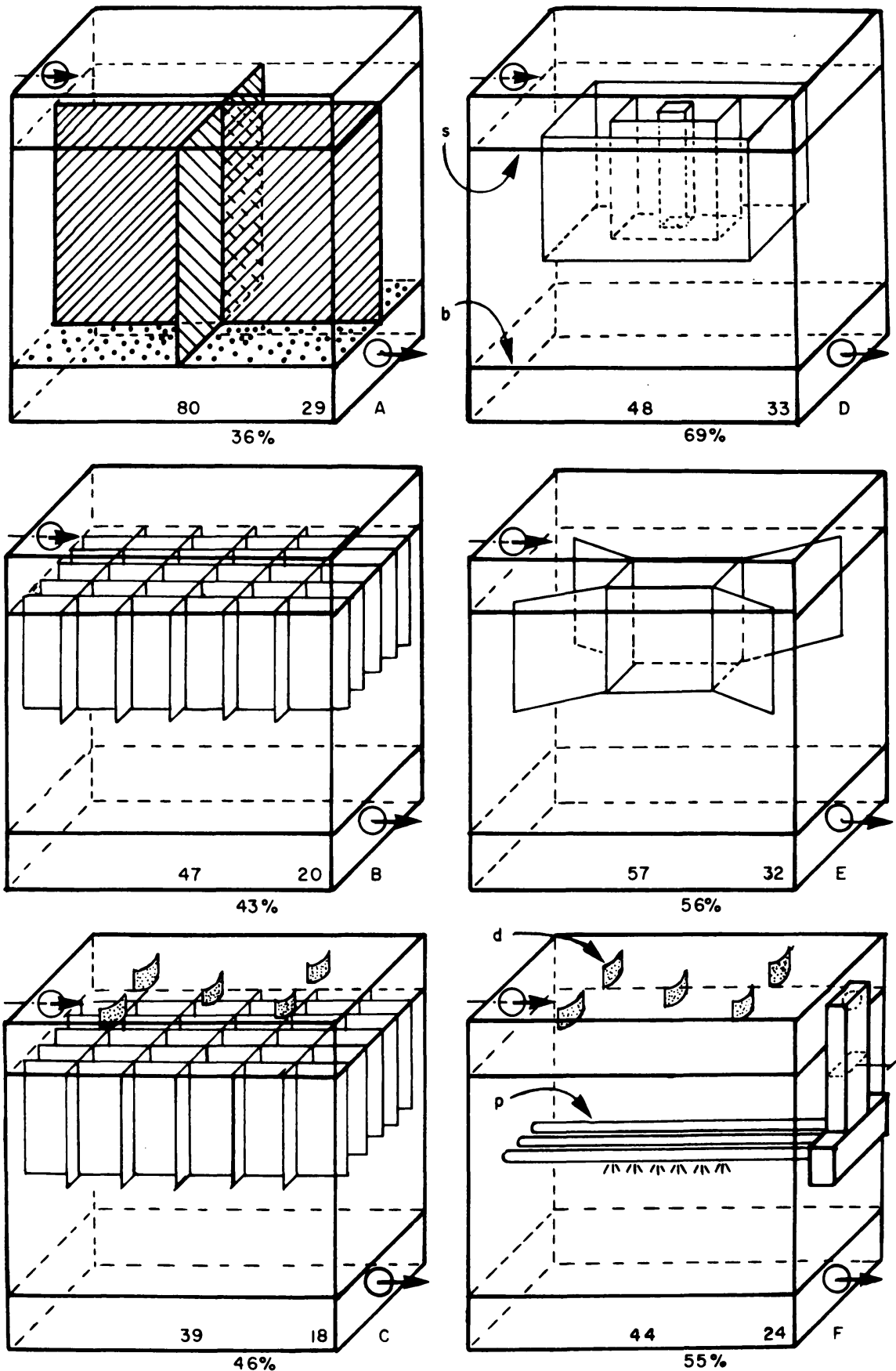

Fig. 4, A-F. Diagram of six configurations of the steam treatment box used in tests to decrease the edge effect during treatment. U.C.-type soil mix was used, and aerated steam was injected into the top plenum. Upper surface of soil $=a$; lower surface of soil $=b$. The time in minutes for the slowest point in the soil mass and at the bottom of the side to reach $60 \mathrm{C}$, and the percentage the latter is of the former, are given for each. A. Four vertical partitions extending to bottom of soil mass. B. "Egg crate" partitions extending halfway to the bottom of soil mass. C. Same as B, plus baffles in top plenum. D. Three squares extending halfway to bottom of soil mass. E. Single square with wings, extending halfway to bottom of soil mass. F. Horizontal pipes with holes in central area, placed halfway to bottom of soil mass and connected with top plenum. Baffles at top $=d$; pipes $=p$. See text for explanations. 
slowly and perhaps thus reach $60 \mathrm{C}$ at the bottom at about the same time as the central soil. This should decrease the flow at the sides, as well as increase the BTU requirement of the sides, and thus retard the rate of heating. To test this reasoning, a half-gallon of water was added to the soil at the sides of the box. The soil was added in 10-cm layers, and wetted along the sides in each case before the next layer was added. Heating at the sides was again more rapid than at the center. Soil at the corners of the box attained $60 \mathrm{C}$ more slowly than at the sides, probably because the corner soil was wetter than that at the sides. It required $63 \mathrm{~min}$ for the slowest bottom center thermocouple to reach $60 \mathrm{C}$, compared to $33 \mathrm{~min}$ at the sides, or 52 percent as long (Fig. $3 \mathrm{~F}$ ).

Vertical Partitions Dividing the Soil Mass.-Thin boards were placed vertically, extending from top (flush with the soil surface) to bottom of the soil mass, dividing it into four quadrants each $46 \times 46 \times 61 \mathrm{~cm}$ (Fig. $4 \mathrm{~A}$ ). The aerated steam tended to flow along both vertical surfaces of the dividers, but the bottom center of each compartment still heated more slowly than the sides. The last bottom point to reach $60 \mathrm{C}$ required $80 \mathrm{~min}$, and the sides $29 \mathrm{~min}$, or 36 percent as long.

Attempts were made to reduce this compartment effect by using smaller compartments. The smallest tested consisted of 36 compartments, each $15 \times 15$ cm in an "egg crate" design, that extended halfway $(30 \mathrm{~cm})$ down into the soil mass (Fig. 4B). The small cross-sectional area of the compartments causes the soil to "bridge" over the space and to adhere to the partitions, making it difficult to empty the container after treatment. When the partitions were flush with the soil surface, the last bottom point to reach $60 \mathrm{C}$ required 47 min, and the sides $20 \mathrm{~min}$, or 43 percent as long. In a similar series of tests, except that the partitions were so placed in the soil that $7.6 \mathrm{~cm}$ projected above the surface, the last bottom point to reach $60 \mathrm{C}$ required 52 min, compared to $35 \mathrm{~min}$ at the sides, or 67 percent as long. Perhaps the projecting tops of the partitions functioned somewhat as the baffles described below. These tests showed that it was not necessary to extend these compartments to the bottom of the soil mass, since the soil with the half-depth dividers heated more rapidly than with full-depth separators. When they extended halfway down, the flow along the vertical surfaces apparently continued on to the bottom before much of the aerated steam was diverted to the sides.

Five slightly curved metal baffles, each $18 \times 8 \mathrm{~cm}$ in the upper plenum (Fig. 4C), improved the distribution of the aerated steam over the soil surface, equalizing the quantity contacting the surfaces of the 36 compartments. The partitions were flush with the soil surface and extended $30 \mathrm{~cm}$ deep. With the baffles, heating at the bottom became more uniform. The slowest bottom point reached $60 \mathrm{C}$ in $39 \mathrm{~min}$, compared to $18 \mathrm{~min}$ at the sides, or 46 percent as long.

A further variant of the last configuration was to reduce the partition depth to $15 \mathrm{~cm}$, inserting the divider flush with the soil surface, and placing a perforated wooden plate on the upper soil surface. Holes $1 \mathrm{~cm}$ in diameter were drilled over the compartments of the "egg crate" as follows: a single hole in the area above each corner compartment, two over each of the other side compartments, and three in each of the 16 center compartments. The last bottom point reached $60 \mathrm{C}$ in $47 \mathrm{~min}$, and the sides in $26 \mathrm{~min}$, or 55 percent as long.

To determine whether modification of the partitions would improve distribution of aerated steam, different shapes of wooden inserts were tested. 
Three squares of thin wooden partitions were placed as shown in Fig. 4D. The inner square was $10 \mathrm{~cm}$ on each side, the middle square $30 \mathrm{~cm}$ on each side, and the outer square $61 \mathrm{~cm}$ on each side. The units were $30 \mathrm{~cm}$ deep and were placed in the soil flush with the surface. The corners of the outer square were $20 \mathrm{~cm}$ from the corners of the box. The slowest bottom point reached $60 \mathrm{C}$ in $48 \mathrm{~min}$, compared to the sides in $33 \mathrm{~min}$, or 69 percent as long.

A series using only the outer $30-\mathrm{cm}$ square of boards projecting $5 \mathrm{~cm}$ above the soil surface was also efficient. The slowest bottom point reached $60 \mathrm{C}$ in 56 min, and the sides in $40 \mathrm{~min}$, or 71 percent as long. The same configuration placed flush with the soil surface was somewhat less effective. The slowest bottom point reached $60 \mathrm{C}$ in $54 \mathrm{~min}$, and the sides in $34 \mathrm{~min}$, or 63 percent as long.

Four thin wooden partitions, each $30 \times 30 \mathrm{~cm}$, were joined in a square as above, and "wings," $30 \times 30 \mathrm{~cm}$, were mounted on each corner (Fig. 4E). The wings reached to within $15 \mathrm{~cm}$ of the box corner. This configuration was placed in the soil, projecting $7.6 \mathrm{~cm}$ above the surface. It required $57 \mathrm{~min}$ for the slowest bottom point to reach $60 \mathrm{C}, 32 \mathrm{~min}$, or 56 percent as long, for the bottom sides.

Variations of this square configuration thus gave fairly even distribution of aerated steam, with some improvement when the squares projected above the soil surface.

Vertical Pipes in the Soil Mass.-To determine whether open vertical pipes would transfer steam to the center of the soil mass, reducing the edge effect and thus equalizing the time required to reach $60 \mathrm{C}$ at the bottom sides and center, the following test was conducted. Five iron pipes, $30 \mathrm{~cm}$ long and $2.5 \mathrm{~cm}$ inside diameter, with open ends, were placed vertically in the soil mass. One was placed $28 \mathrm{~cm}$ diagonally in from each corner of the box, and one was in the center. The pipes projected $1.3 \mathrm{~cm}$ above the soil surface. Five baffles were placed in the upper plenum as shown in Fig. 4C. The slowest bottom point reached $60 \mathrm{C}$ in $45 \mathrm{~min}$, and the sides in $29 \mathrm{~min}$, or 64 percent as long. This is a fairly effective means of equalizing time of heating the soil mass between the bottom center and sides. If the pipes are thrust into the soil mass they become clogged with soil. However, the pipes could be permanently mounted on iron braces attached to the sides of the box just below soil level and $3 \mathrm{~cm}$ above the lower end of the pipes. The tops of the pipes could be capped while the box was being filled with soil, and the caps then removed before steaming was started. A modification of this has been used in commercial soil treatment units in New Zealand, where a single open pipe, $10 \mathrm{~cm}$ in diameter, is placed in the center of the box which holds $3.8 \mathrm{~m}^{3}\left(5 \mathrm{yd}^{3}\right)$ of soil.

Steam Released into the Middle Center of the Soil Mass from Horizontal Perforated Pipes.-Three pipes of 3.8 $\mathrm{cm}$ inside diameter, placed horizontally $15 \mathrm{~cm}$ apart and $30 \mathrm{~cm}$ down from the soil surface, were connected on the outside of the box with a duct that led to the top plenum. Each pipe had 12 0.63-cm holes drilled $2.5 \mathrm{~cm}$ apart along the center of the underside (Fig. $4 \mathrm{~F}$ ). The total cross-sectional area of the holes was equal to the cross-sectional area of the duct from the plenum. A tight metal collar, $12 \mathrm{~cm}$ in diameter, was placed on each pipe $28 \mathrm{~cm}$ from the sides of the box to prevent lateral flow along the undersides of the pipes. Five baffles, each $18 \times 8 \mathrm{~cm}$, were placed in the upper plenum (Fig. 4F). A manually operated valve controlled the flow of aerated steam to the pipes from the top plenum. During operation, the aerated steam was introduced into the top 
plenum with the valve to the pipes closed. When the advancing steam front was 2.5 to $5 \mathrm{~cm}$ above the pipes (determined through thermocouples; about $15 \mathrm{~min}$ ), the valve was opened. Each of the aerated steam jets from the pipes heated an area at the bottom $(28 \mathrm{~cm}$ below) about $7.6 \mathrm{~cm}$ in diameter. A bottom central area, $38 \times 38 \mathrm{~cm}$, was thus completely blanketed with aerated steam while the steam was moving down the sides of the box. The slowest central bottom point reached $60 \mathrm{C}$ in $44 \mathrm{~min}$, and the sides in $24 \mathrm{~min}$, or 55 percent as long.

In another series, in which the plenum valve was open only for the first $15 \mathrm{~min}$ of operation, the slowest bottom point reached $60 \mathrm{C}$ in $50 \mathrm{~min}$, compared to $32 \mathrm{~min}$ at the sides, or 64 percent as long. Some of the thermocouples reached $60 \mathrm{C}$ before the valve was shut, then cooled somewhat by heat transfer, and subsequently reheated as the advancing front from the top plenum reached that point.

A test was run in which two pipes, 3.8 $\mathrm{cm}$ in diameter, were placed horizontally $30 \mathrm{~cm}$ deep and $38 \mathrm{~cm}$ from each side. The two pipes were $15 \mathrm{~cm}$ apart. The collars and perforations in the pipes were as described above. The slowest bottom point reached $60 \mathrm{C}$ in $54 \mathrm{~min}$, and the sides reached that temperature in 30 min, or 56 percent as long.

The box was then converted to a perforated-pipe steam box (Type 4, Baker and Roistacher, 1957), with four layers of five pipes each. There was considerable improvement in uniformity of heating the soil because the aerated steam was distributed through the soil mass rather than diffusing through it.

\section{Steam Flow Pattern, Visually Determined}

Although thermocouples placed throughout the soil mass and close to the sides of the box provided data for plotting the boundaries of the advanc-

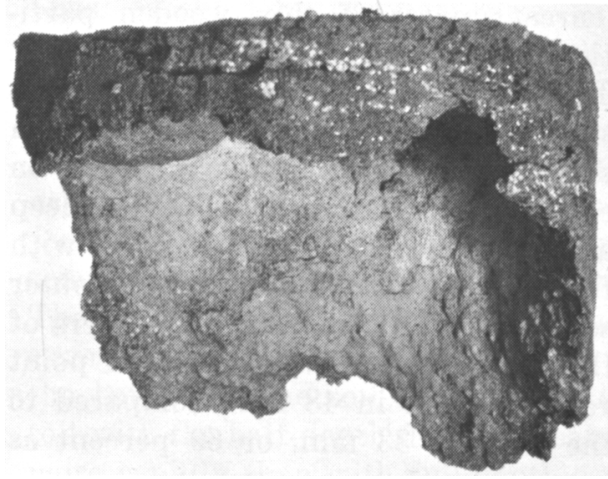

Fig. 5. Plaster cast of area heated by steam in soil mass, showing the tendency for steam to flow down the sides of the container. The near side of the cast was broken away to show the central hollow where the steam had not penetrated. See text for details.

ing front, information was desired on the shape of these boundaries. The following method was devised to provide this.

A round steel can, $18 \mathrm{~cm}$ in diameter and $30 \mathrm{~cm}$ deep, was filled to a depth of $25 \mathrm{~cm}$ with a $1: 1: 2(\mathrm{v} / \mathrm{v})$ mixture of calcium chloride, calcium sulfate (plaster of Paris), and fine dry sand. Cheesecloth was tied over the open end, and the can was inverted over a coarse screen. A rapid flow of dry aerated steam was introduced through the top center of the inverted can, below which a baffle was positioned to prevent jet penetration of the soil. After 3-4 min of steaming, when the sides had been heated (shown by thermocouples), the steam was shut off and the mixture allowed to harden for $30 \mathrm{~min}$. When the cheesecloth was removed, the nonheated soil flowed out, leaving a hardened cast of the soil into which steam had flowed. The aerated steam had moved equally down all sides of the can. For photographing, the near side of the cast was broken away (Fig. 5). A smaller steam flow gave a thicker area of flow down the sides and at the top. The steam was wetter than for Fig. 5, and a thicker cast resulted (Fig. 6 ). 


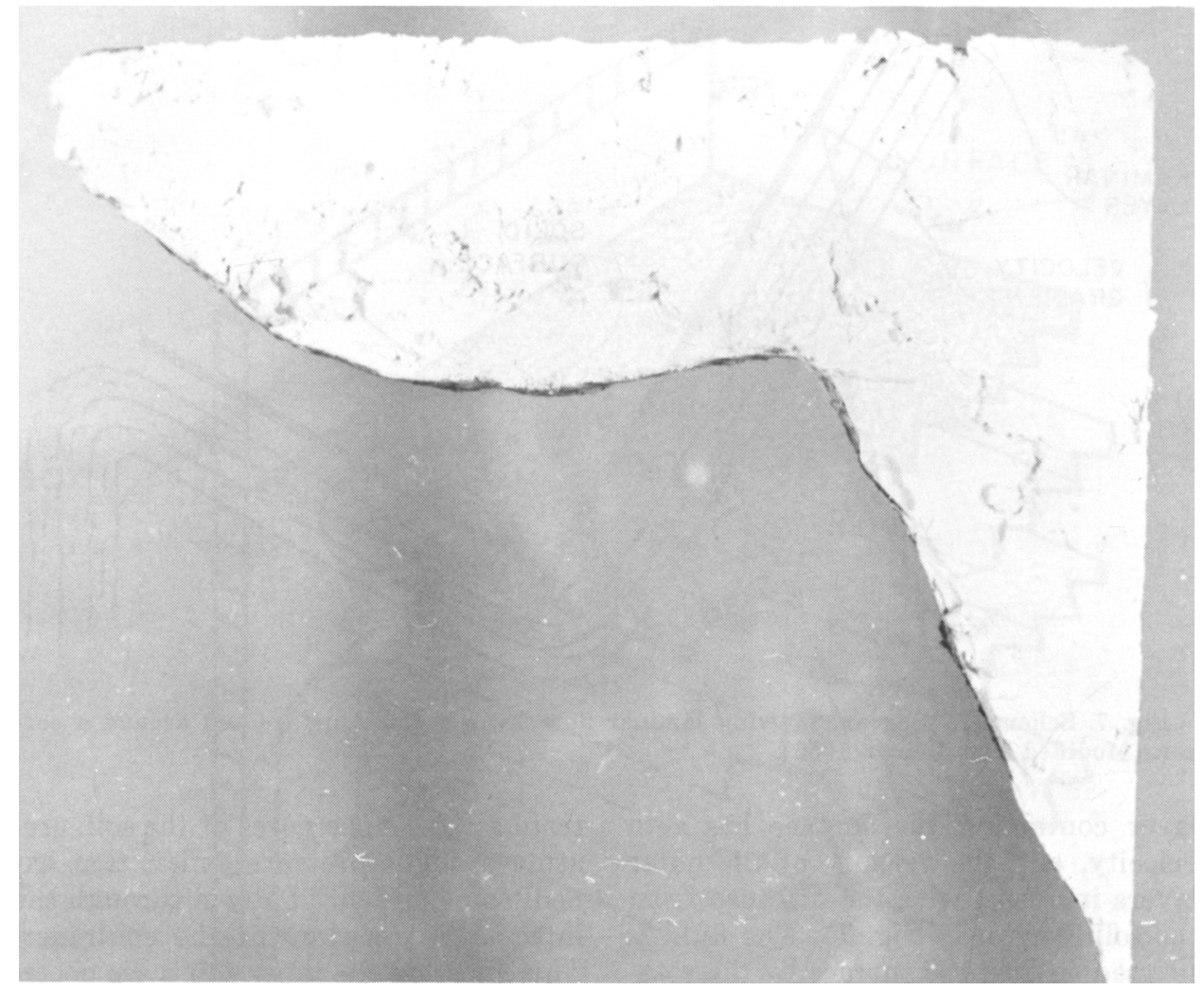

Fig. 6. Vertical section of the right half of a plaster cast of the area heated by steam in a soil mass, showing the tendency for steam to flow down the sides. The steam was wetter than that in Fig. 5, and consequently a thicker cast resulted at the top. See text for details.

\section{HYPOTHESES FOR THE CAUSE OF THE EDGE EFFECT}

The explanation for the edge effect in steaming soil is not resolved, and may involve more than one process.

1. Greater porosity at the soil-side than at the soil-soil interface.-This hypothesis (Baker, 1971) is supported by the faster movement of aerated steam down the sides of the container than through the central soil mass (Figs. 1, 2, $3 \mathrm{~A}-\mathbf{E})$, despite various structural modifications to prevent it. However, cementing sand onto the sides of the box to overcome the increased porosity resulting from contact of soil with a smooth surface did not diminish the edge effect. It is not known whether this procedure actually reduced soil porosity at the interface.

2. Coanda effect.-A fluid (either gas or liquid) tends to cling to or "lock onto" a surface that is near an orifice from which the fluid emerges (Reba, 1966). When the flow rate is low, this has been called the "teapot effect," from the homologous tendency of a liquid to run down the spout when poured from a teapot (Reiner, 1956). The physical explanation of this type of Coanda effect has been discussed by Reiner (1956). A fluid flowing along a solid surface is laminar, its several layers flowing at different rates. The fluid 




Fig. 7. Schematic diagram showing laminar flow along a solid surface and around a corner. (Modified from Reiner, 1956).

layer contacting the surface has zero velocity, and the velocity of the outer layers increases with the distance from the solid surface (Fig. 7). The fluid is pressed against the surface by the rotational kinetic energy of the vortices, the effect being similar to waves breaking on an ocean beach. As each wave reaches shallow water, the frictional drag of water against the bottom reduces velocity at this point until the top of the wave "breaks." As surfers know, there is intense rolling under of the advancing front; this is similar to the vortices of the Coanda effect. As Reba (1966) pointed out, the vortices of the laminar flow may draw in fluid from the surroundings, since the pressure at the surface is less than at the outermost lamina.

A hypothetical application of the Coanda effect to the edge effect in steam treatment of soil is shown in Fig. 8. Steam may move upward or downward along the walls of the container in laminar layers, depending on whether it is injected through a basal or a top plenum. The rotational vortices may en- train air from the pores of the soil, creating a slight pressure deficit that expedites movement of steam through the interior to the sides of the container. This effect on the inner soil mass necessarily would lag behind the source of the effect, the advancing front along the side walls. There is also increasing bulk density of the soil mass with depth in the container. The air flows along the lines of least resistance as it is displaced by steam, and thus flows laterally to the zone of low pressure along the sides, increasing the laminar flow there. The steam then tends to follow the air.

When aerated steam is injected through the top center of the upper plenum of a square (Figs. 1,2) or a round container (Figs. 5, 6), it tends to move fairly uniformly down the sides, and faster than in the center of the soil mass. This could be consistent with the Coanda effect. When aerated steam is injected through the side of the upper plenum (Figs. 3, 4), it might be argued that movement by the Coanda effect should largely be down the side through which it is injected. However, it is 


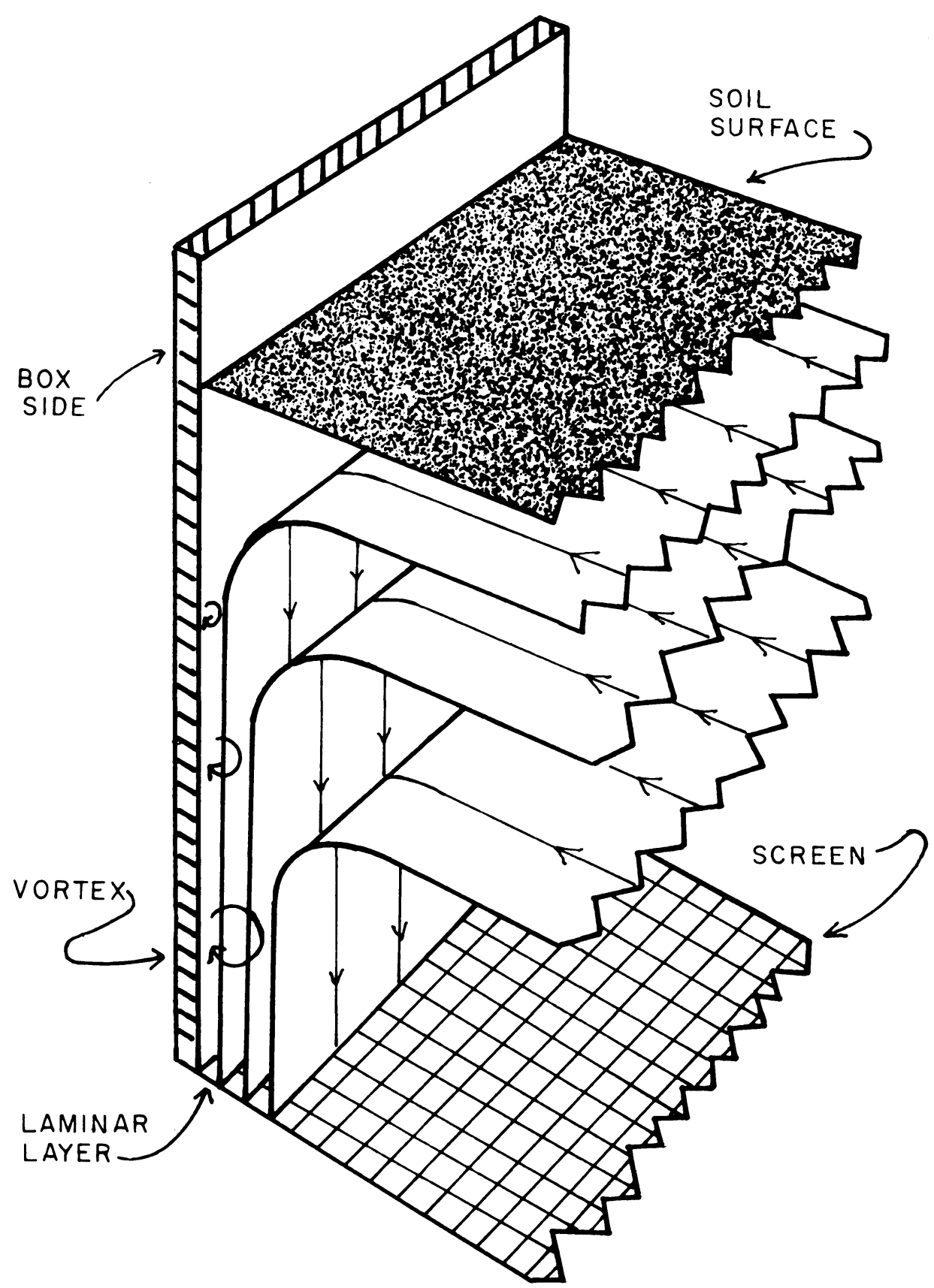

Fig. 8. Schematic diagram of the hypothetical laminar flow and Coanda effect in steaming soil in a treatment box. Steam, injected at the top, moves down through the soil mass, but is increasingly drawn into the laminar flow along the side of the box. The central area at the bottom, therefore, reaches the desired temperature more slowly than does the side. 
known (Reba, 1966) that an injection nozzle must be precisely designed to achieve such angular deformation of the flow. Also, there is no such nozzle on a teapot. Aerated steam injected into a plenum through a side port tends to impact on the opposite wall and, to some extent, on the side walls. It is undetermined whether this would lead to its clinging to these surfaces, as in the teapot effect.

3. Heat conduction by side walls of the container.-This suggested explanation is not applicable, because the edge effect occurs whether the container has metal (Figs. 5, 6) or plywood sides (Figs. 3, 4). The thermal conductivity of steel is more than 300 times, and of wrought iron more than 400 times, that of wood. The edge effect should be negligible in containers with wooden sides if this were the explanation. However, the aerated steam moves down wooden as well as metal sides.

4. Condensation of steam on the side walls.-Although the specific heat (heat capacity) of wood is about four times that of steel, the higher thermal conductivity of steel would also involve greater heat loss by convection and radiation from the outside of the container than would be the case from wooden sides. The specific heat of soil with 20 percent water by weight would be nearly the same as that of the wooden sides. With either wooden or steel sides there would be some condensation in heating the sides, but it would not exceed that occurring in the soil mass. It is therefore unlikely that this factor could be responsible for the edge effect.

\section{DISCUSSION}

The operation of the edge effect in passage of steam or aerated steam upward or downward through soil during steam treatment appears to be an unavoidable physical fact. When the soil mass is more than $30 \mathrm{~cm}$ thick, the effect can only be diminished somewhat. Although it is relatively unimportant when the soil is $20-25 \mathrm{~cm}$ thick, because there is insufficient time for the steam to move to the sides, it does still occur. The effect is also diminished in very porous soil mixtures, because the minimal friction involved in steam movement through the center of the mix apparently decreases the lateral displacement from the edge effect.

An anomalous situation is provided by the triangular wooden pieces frequently placed in the vertical corners of steam boxes used for soil treatment. When steam is injected into the soil through a grid of perforated pipes (Baker and Roistacher, 1957, Type 4), the corners, particularly near the bottom, are apt to be slow heating. The edge effect is minimal because the steam is injected directly into the soil mass, and diffuses outward to the walls. The triangular blocks tend to preclude "cold corners" by excluding soil from those areas that are slowest to heat. When steam is injected into containers with top or bottom plenums, however, the edge effect is strongly operative, and the steam flows down the sides. In the corners under these conditions, the convergence of the two planes of steam flow apparently tends to make for faster heating there than at the sides. Triangular blocks in these "hot corners" will tend to concentrate the steam movement there, with resulting steam loss, and possible "blowouts" if steam is injected from the bottom.

The tendency of steam to advance more rapidly along the sides than at the center of the container may be a serious problem in steam treatment of soil in the mobile bin and potting table (Type 3, Baker and Roistacher, 1957), and a slight one with the Thomas or 
surface method (Type 5). Apparently it is not important in vault steamers (Type 6), transit-type concrete mixers used for soil steaming, buried perforated pipes or tiles (Type 20), or the moving steam blade.

The edge effect in steam boxes and bins may best be reduced by using a layer of soil $20-30 \mathrm{~cm}$, at most $45 \mathrm{~cm}$, deep. Vertical partitions extending from about $5 \mathrm{~cm}$ above the soil surface down to half the soil depth, or open pipes in the central mass, apparently are the best mechanical means for reducing this effect. The flow rate of steam or aerated steam should be large. When the flow is large, the chances of "blowouts" may be reduced by injecting the steam from the top rather than from the bottom.

Temperature measurements should be made at the bottom center of the soil when steam injection is from a top plenum, and at the top center when injection is from a bottom plenum.

\section{LITERATURE CITED}

AldRICH, R. A.

1971. Design of systems for aerated steam treatment of soil and soil mixes. 9 pp. Mimeo. Dept. Agr. Engineering, Penn. State Univ., University Park, Penn.

Aldrich, R. A., P. J. Wuest, and J. A. McCurdy

1974. Treating soil, soil mixtures, or soil substitutes with aerated steam. Penn. Agr. Ext. Serv. Spec. Circ. $182: 1-14$.

Aldrich, R. A., M. E. Schroeder, R. A. Keppeler, and G. H. Diener

1975. Heating soils, soil mixes, and soil substitutes with saturated air. Penn. Agr. Exp. Sta. BAKER, K. F. Bull. 800:1-38.

1967. Control of soil-borne plant pathogens with aerated steam. Proc. Wash. State Univ. Greenhouse Growers Inst. 1967:3-18.

1969. Soil treatment. pp. 40-52. In J. W. Mastalerz and R. W. Langhans (ed.), Roses. 331 pp. Roses Inc., Haslett, Mich.

1971. Soil treatment with steam or chemicals. pp. 72-93. In J. W. Mastalerz (ed.), Geraniums. 2nd ed. 350 pp. Penn. Flower Growers, University Park, Penn.

BAKER, K. F., and C. M. OLSEN

1960. Aerated steam for soil treatment. Phytopathology 50:82.

BAKER, K. F., and C. N. RoIsTACHER

1957. Heat treatment of soil. Principles of heat treatment of soil. Equipment for heat treatment of soil. Calif. Agr. Exp. Sta. Manual $23: 123-196,290-293,298-304$.

JoHnson, D., and K. AAS

1960. .Investigations of the technique of soil steaming. Acta Agr. Scand. Suppl. 9:1-69.

MORRIS, L. G.

1954a. The steam sterilising of soil. Experiments on fine soil. Natl. Inst. Agr. Engineering Rept. 14:1-32.

1954b. The steam sterilising of soil. The application of research to practice. Natl. Inst. Agr. REBA, I. Engineering Rept. $24: 1-22$.

1966. Applications of the Coanda effect. Sci. Amer. 214: (6) :84-92.

REINER, M.

1956. The teapot effect ... a problem. Physics Today 9: (9) :16-20. 

The journal HILGARDIA is published at irregular intervals, in volumes of about 650 to 700 pages. The number of issues per volume varies.

Single copies of any issue may be obtained free, as long as the supply lasts; please request by volume and issue number from:

\author{
PUBLICATIONS \\ UNIVERSITY OF CALIFORNIA \\ DIVISION OF AGRICULTURAL SCIENCES
}

1422 South 10th Street

Richmond, California 94804 


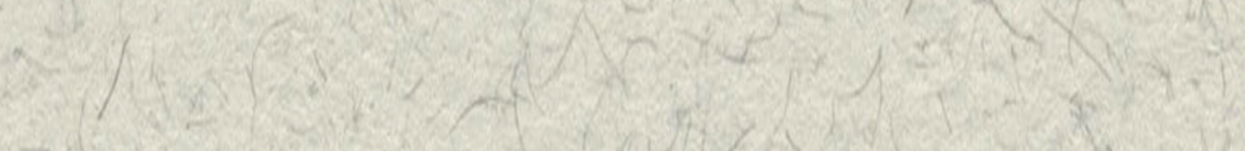

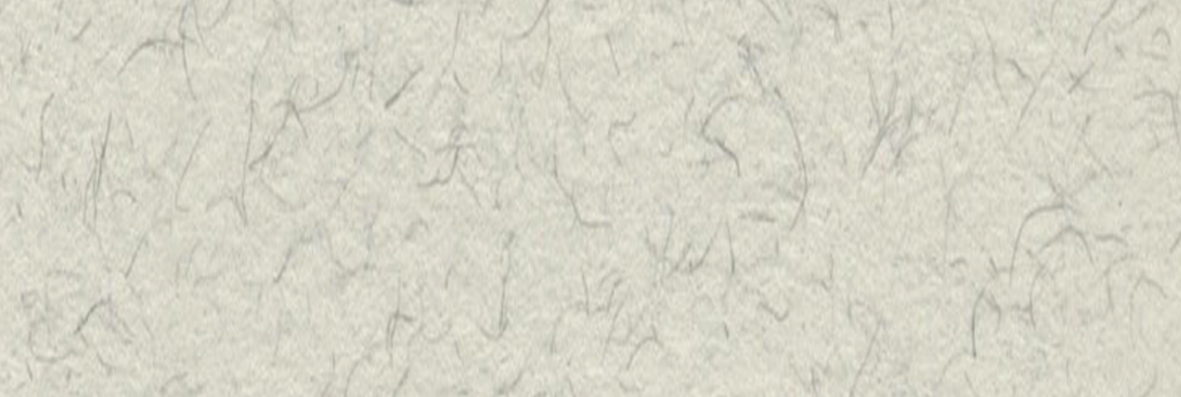

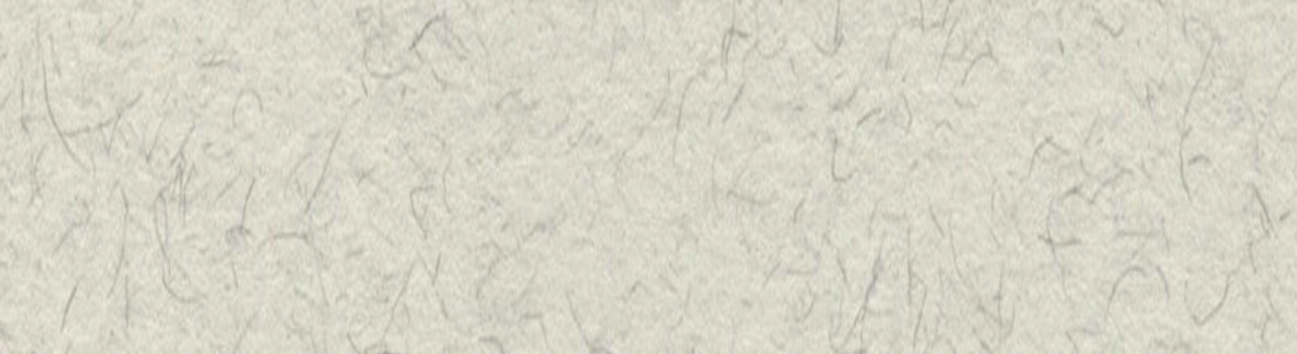

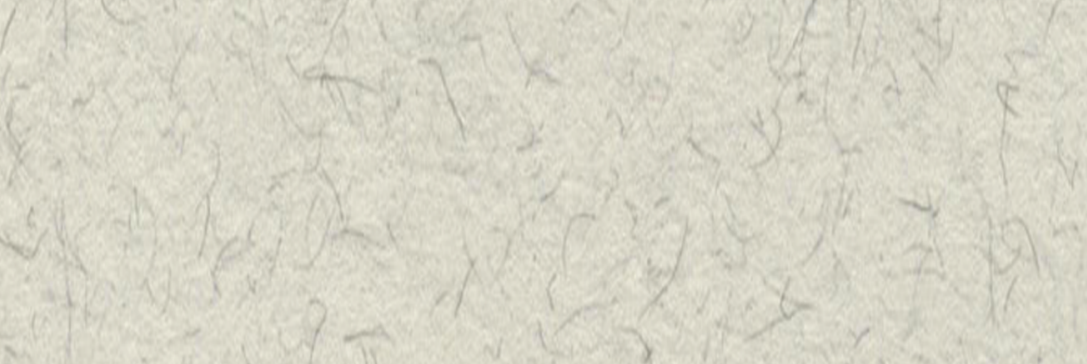

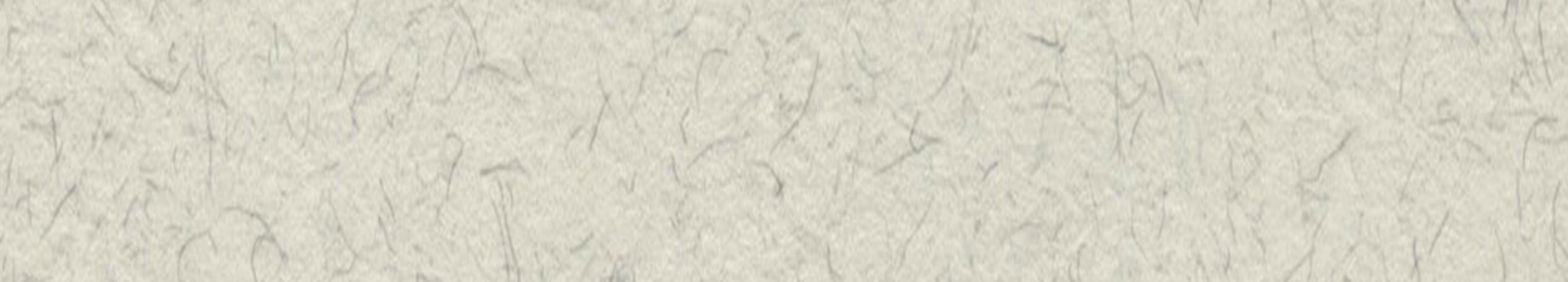

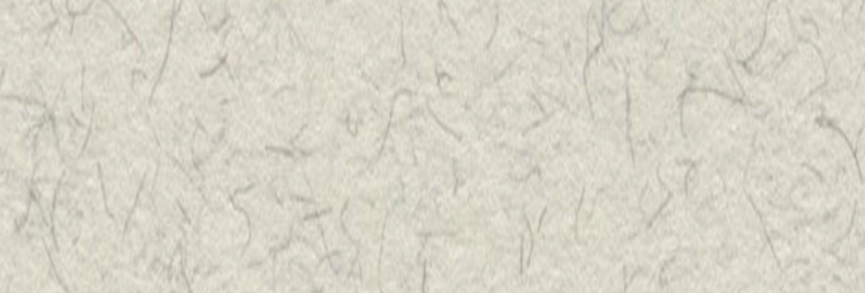

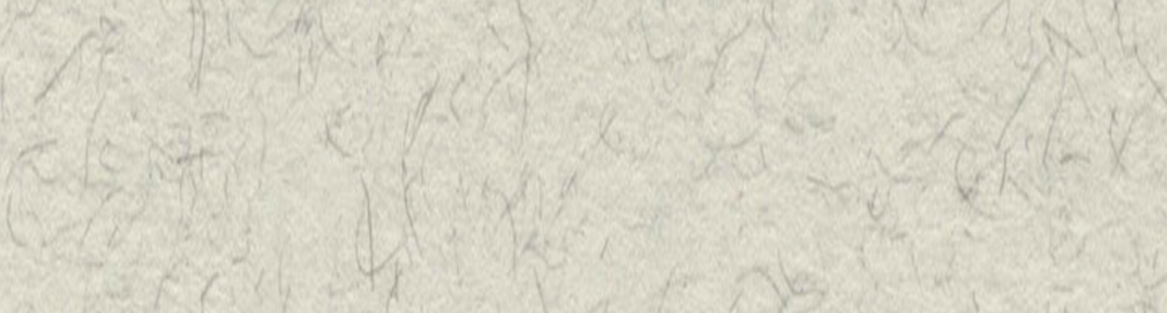

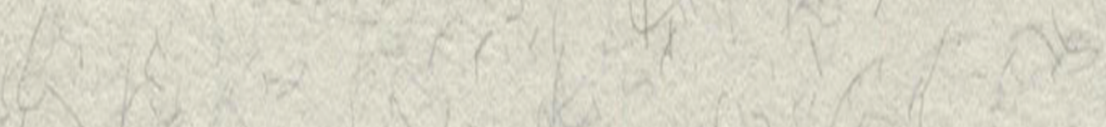

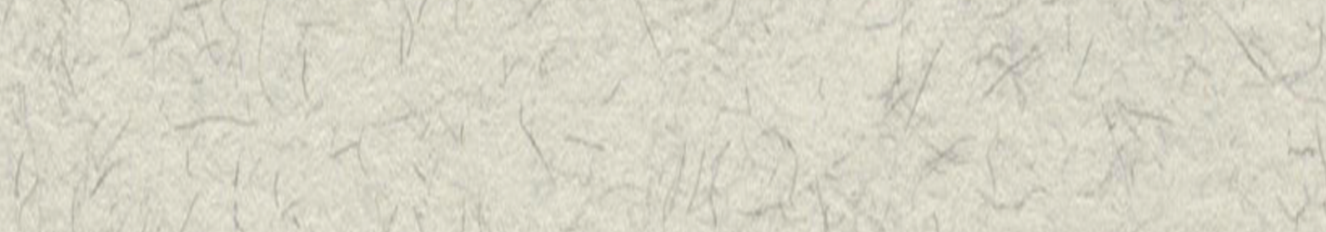

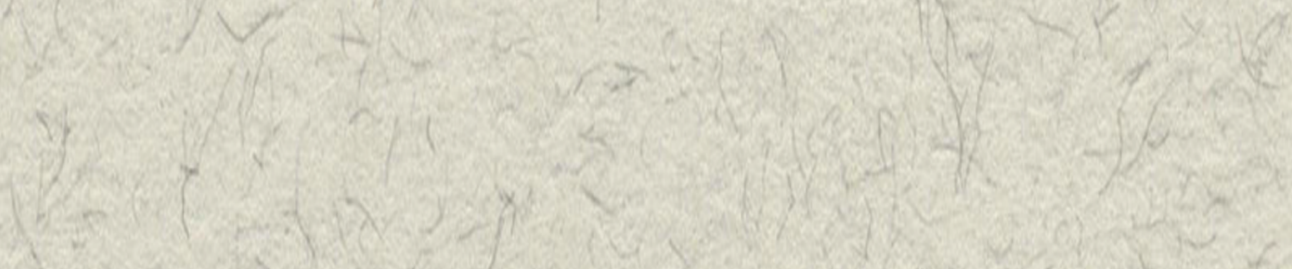

